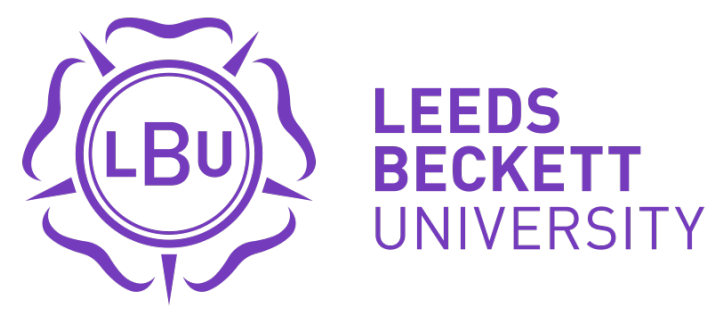

Citation:

Atkin, K and Madden, M and Morris, S and Gough, B and McCambridge, J (2020) Community pharmacy and public health: preserving professionalism by extending the pharmacy gaze? Sociology of Health \& IIIness. ISSN 0141-9889 DOI: https://doi.org/10.1111/1467-9566.13221

Link to Leeds Beckett Repository record:

https://eprints.leedsbeckett.ac.uk/id/eprint/7496/

Document Version:

Article (Accepted Version)

This is the peer reviewed version of the following article: Atkin, K., Madden, M., Morris, S., Gough, B. and McCambridge, J. (2020), Community pharmacy and public health: preserving professionalism by extending the pharmacy gaze?. Sociol Health IIIn., which has been published in final form at https://doi.org/10.1111/1467-9566.13221. This article may be used for non-commercial purposes in accordance with Wiley Terms and Conditions for Use of Self-Archived Versions.

The aim of the Leeds Beckett Repository is to provide open access to our research, as required by funder policies and permitted by publishers and copyright law.

The Leeds Beckett repository holds a wide range of publications, each of which has been checked for copyright and the relevant embargo period has been applied by the Research Services team.

We operate on a standard take-down policy. If you are the author or publisher of an output and you would like it removed from the repository, please contact us and we will investigate on a case-by-case basis.

Each thesis in the repository has been cleared where necessary by the author for third party copyright. If you would like a thesis to be removed from the repository or believe there is an issue with copyright, please contact us on openaccess@leedsbeckett.ac.uk and we will investigate on a case-by-case basis. 


\title{
COMMUNITY PHARMACY AND PUBLIC HEALTH: PRESERVING \\ PROFESSIONALISM BY EXTENDING THE PHARMACY GAZE?
}

\author{
Karl Atkin 1, Mary Madden ${ }^{1}$, Stephanie Morris ${ }^{2}$, Brendan Gough ${ }^{3}$, and Jim \\ McCambridge ${ }^{1}$
}

1. Department of Health Sciences, University of York

2. Department of Anthropology, University of Durham

3. School of Social Sciences, Leeds Beckett University

\section{ABSTRACT (200 words)}

Community pharmacy faces ongoing challenges to its economic and social standing. A concern to legitimate professional status explains the attraction of public health. Interventions currently advocated by UK State-sponsored healthcare seek to reconcile the autonomous 'entrepreneurial' patient with market-driven solutions. Engaging critically with recent Foucauldian sociological work on pharmacy as a conduit for disciplinary power, we explore how professional ambiguity is exploited to 'manage' the subjectivities of community pharmacists. Locating our discussion in the observed empirical realities of pharmacy practice, (the inclusion of alcohol and other 'healthy living' advice in the Medicines Use Review) we connect unresolved historical debates in community pharmacy with current ongoing (neoliberal) changes in policy and pharmacy business practices, drawing attention to the poor evidence base underpinning healthy living activities in community pharmacy. Our findings show how community pharmacists struggle to provide meaningful advice, valued by patients. Instead of enhancing professional status, 'add-on' public health roles created the risk of offering little more than an essentialised enactment of consumerist healthcare. Understanding how patients conceptualise drinking and 'healthy-living' in relation to their long-term health, using more open discussions, including the negotiation (rather than provision) of information, 
could help community pharmacists challenge the current professional vulnerabilities they face.

Key words: community pharmacy, patient-centred-care, public health, professional role, alcohol, qualitative research

\section{INTRODUCTION}

In the UK (and elsewhere) community pharmacy occupies an ambiguous professional position as it searches for a credible role within the changing context of modern healthcare (Martin and Waring, 2018). The struggle for professional standing is long-standing and much of the debate has been focused on pharmacy's subordination to medicine (McDonald et al., 2010, Cooper et al., 2009). UK community pharmacy is currently sited in the fragmented internal market of a reorganising National Health Service (NHS) facing workforce challenges in primary care (NHS, 2019; Iacobucci, 2017). Community pharmacists, as private contractors engaged by the NHS, provide local pharmaceutical services within a retail setting, in addition to a range of products for customers to purchase. Amidst concerns of its demise, and by aligning traditional claims to expert and altruistic practice with emerging discussions associated with patient choice, the profession has developed an interest in public health (Walker, 2000; Waring et al., 2016, Cooper, 2020).

Taking on an extended role within the corporate and policy rationalities of healthcare reorganisation carries risk as well as opportunity. Drawing on recent Foucauldian analyses of the changing forms of power brought about by community pharmacists assuming an extended role, here we locate this risk empirically in the 'healthy living' aspect of The Medicines Use Review (MUR). The MUR, introduced by the 2005 NHS Community Pharmacy Contractual Framework (CPCF), offers a form of remunerated patient engagement, which since 2012 has 
included 'healthy-living advice'. Pharmacists are expected to advise on alcohol, smoking, physical activity, nutrition, weight management and/or sexual health (PSNC and NHS Employers., 2012). By focusing on this advice as negotiated in practice, rather than relative to an idealised professional role described in policy and supported by professional rhetoric, we examine how a governmentality that privatises risk finds expression in community pharmacy (Rose, 2009). We specifically question the extent to which 'the pharmacy gaze' (Jamie, 2014) is being extended and whether pharmacists are assuming the responsibility for shaping patients' self-regulating subjectivities associated with 'pastoral power' (Waring et al., 2016).

\section{BACKGROUND}

\section{Navigating neoliberal health norms}

As the twentieth century ended, Governments became increasingly concerned with reducing dependency on State-sponsored welfare by promoting market-orientated solutions (Martin and Waring, 2018). Community pharmacists, like other healthcare professions, accept responsibility for ensuring the normative operation of these concerns in exchange for maintaining professional standing (Waring et al., 2016, Dingwall, 2008). In doing so, they navigate: growing deregulation of pharmaceutical sales; the commercial expediencies of increasingly large corporate-owned pharmacies; an increasing use of targets to which remuneration is tied; comparisons with medical professionals; and expectations to extend professional roles (Bush et al., 2009, Taylor and Harding, 2003).

Many current public health interventions, by privileging individual empowerment at the expense of collective action and structural reform, reflect the ordering influence of neo- 
liberalism (Popay et al., 2010). Preventative strategies, principally involving the provision of information and advice, are not only regarded as cost-effective, but encourage individual action and personal responsibility, independent of direct State intervention. Professions are called on to facilitate these expectations, help promote desirable subjectivities and introduce risk management (Rose, 2007). Recent Foucauldian inspired-work has explored the idea of 'inscriptive confessional practices' in healthcare, whereby 'pastoral' activity might inspire patients to internalise values, as a form of governmentality in which obligation becomes associated with responsibility (Martin and Waring, 2018). The individual subject is thereby rendered 'entrepreneurial' (Brown, 2015) and following purposeful conversations administrated by professionals, risk is privatised through the exercise of 'pastoral' care (Waring et al., 2016; Foucault, 2007). Taking on a more 'pastoral' role requires responding to broader transformative ideas about 'the patient', while operating within a changing mercantile environment, in which the demands of the 'market' generate tensions with altruistic practice (Waring et al., 2016).

Beginning with Denzin and Mettlin's (1968) paper on the 'incomplete professionalization' of pharmacy, sociological work has questioned the extent to which community pharmacy has been motivated by commercial rather than altruistic goals, particularly since it ceded control to the pharmaceutical industry of the social object (the drug) around which it is organised, while accepting payment from the State for performing certain activities (Martin and Waring, 2018). From compounding and transforming drugs into medicines, the pharmacist has become an agent through which medicinal drugs and devices are safely distributed and their purpose understood (Harding and Taylor, 1997). Contracting to meet State agendas poses limitations on professional autonomy in an occupation sometimes seen as a 'trade' (Bush et al., 2009), in which patient interactions are short, instrumental, transactional and over-thecounter. Pharmacists conduct the required legal, clinical and accuracy checks on medicines 
in the dispensary, leaving occasionally to provide information or respond to customer inquiries about medicines and health-related products. Much patient contact is delegated to counter staff and interactions are often with proxies (friends and relatives collecting medicines) rather than the patient themselves (Cooper et al., 2009).

\section{Extending community pharmacy}

Calls to extend the role of community pharmacists, dating back to the Nuffield report (1986), have emphasised their relative availability and approachability rather than the depth or exclusivity of their knowledge. The availability of pre-packed medicines without prescription in retail outlets other than pharmacies, has undermined the pharmacist's customary role in dispensing medicines (Harding and Taylor, 1997). Detailed information leaflets, the rise of the 'expert patient' and increased online availability of medicines (and medicines' information) further reduce reliance on pharmacists' expert knowledge and the physical pharmacy space (Cooper, 2020).

Current enthusiasm for extending pharmacy services, including advice on 'healthy-living', is linked to a sense that the third largest healthcare profession (globally) is an 'untapped' resource able to contribute positively to community well-being (Murray, 2016, p3). Becoming a 'hub enabling people to lead healthier lives' creates possible futures in which community pharmacists become a recognised asset for improving public health (Department of Health, 2016 p1). However, the 'routines, relationships and rituals' that construct everyday professional practice can generate challenges (Waring and Bishop, 2011 p664). The ongoing promotion of pharmacy services as available without appointments, unlike the 'over-burdened' General Practitioner (GP), assumes the availability of pharmacists. This somewhat contradicts a professionalising strategy that encourages the public to view 
pharmacist's time as valuable. Patients, for their part, perceive the core dispensing process as a retail exchange of prescription-form and drug (NICE, 2020). They rarely recognise the pharmacists' role in supporting self-care (Elvey et al., 2013), considering the GP a more qualified source of information (Latif, 2017). Further, the annual survey published by Chemist and Druggist in (2019) stated that 74 per cent of pharmacists identified as experiencing workplace stress, with little capacity to take on additional work. The preventative public health work pharmacists 'are ready and willing to assume' (PHE, 2016 p3), also continues to be less resourced than dispensing and clinical health roles (Health Foundation and Kings Fund, 2019).

Earlier attempts at the 'reprofessionalization' of community pharmacy included a basic role in 'health promotion', such as being contracted to display posters and leaflets (Bush et al., 2009). Pharmacy's focus on providing individual services and its restricted potential to engage with the structural and political causes of ill health at the population level have been identified as limitations in its approach to public health (Jesson and Bissell, 2006; Walker, 2000). There have been few accompanying recommendations on how the profession might practically address this (Bush et al., 2009). The 'positive pharmacy care law' (Todd et al., 2014), refers to the potential pharmacies have in reducing inequalities in 'priority public health conditions' given that pharmacy density is greater in areas of highest deprivation. This study considers only geographic proximity and not availability or accessibility of services. Arguably, pharmacy density in disadvantaged communities is not surprising given that poor health creates a market for medicines. The potential pharmacy resource identified could also be seen as a reflection of pharmaceutical overtreatment (Godlee, 2019). A recent review of reviews of community pharmacy-delivered public health interventions identified evidence of effects of some services (e.g. smoking cessation, syringe/needle exchange and inoculation) 
but little evidence on health inequalities (Thomson et al., 2019). Evidence remains lacking on whether increased leaflet uptake has any impact on health behaviour change (NICE, 2020).

A growing number of pharmacies adopted the Healthy Living Pharmacies (HLP) framework before it was made compulsory in the latest CPCF (DHSC, 2019). The new contract requires HLPs to create teams that are aware of local health issues and consistently demonstrate they are promoting public health (DHSC, 2019). In 2019, over $80 \%$ of community pharmacies in England declared themselves an HLP (level 1) (PSNC, 2020a). This is despite a lack of evidence on effectiveness in improving health outcomes (Nazar et al., 2019). There is some evidence that pharmacists have considered levels of HLP remuneration insufficient to divert their focus from dispensing (Langley et al., 2014). This explains why such activities are mostly delegated to non-pharmacist staff (Eades et al., 2011). When considered alongside community pharmacists' formal lack of public health knowledge (Bush et al., 2009), it is not difficult to appreciate the challenges of establishing a 'hub' facilitating healthy-living (Anderson et al., 2003).

\section{Contract and trade considerations}

Payments associated with contractual activity carry the risk that community pharmacy becomes defined by policy rather than professional practice (Martin and Waring, 2018). Traditionally, the majority of community pharmacies operated as independent businesses, run by owner-managers. There is now increasing ownership by multiple contractors. The 2005 $\mathrm{CPCF}$, by opening the way for supermarket, primary care and distance-selling pharmacies, resulted in larger businesses providing dispensing services (Hann et al., 2017). The rise of large-scale corporate pharmacies and the demands of efficiency, routinisation, predictability and standardisation, referred to as 'McDonaldization' further constrains professional autonomy (Ritzer and Elizabeth, 2000; Harding and Taylor 2000; Bush et al., 2009). Expert 
advice is reduced to formulaic, (a)contextual application with little opportunity for professional discretion (Lipsky, 2010).

Consequently, the relative commercial advantages of taking on additional commissioned services to compensate for reductions in NHS funding (DH, 2016), have to be weighed against providing products (trade) and private services (fees) that encourage the marketisation and commodification of healthcare (Kickbusch and Payne, 2003). These include screening and monitoring, in addition to cosmetic products and services (Finch, 2018). Pharmaceutical companies are also increasingly moving into the 'wellness' market, with over-the-counter and prescription dietary supplements, preventive medicine and 'lifestyle' drugs to treat life-course 'conditions' such as baldness and impotence. Examples of State-paid contract services include remuneration for displaying health promotion materials; providing influenza vaccination; and offering general (rather than specialist) health advice via medicines' management (Mackridge et al., 2017). All of which provide little opportunity to demonstrate professional competence (Hann et al., 2017).

\section{STUDYING ROUTINE PRACTICE}

Our analysis explores how community pharmacists negotiate these challenges, while attempting to enhance their professional standing, by drawing on qualitative material collected as part of a five-year research programme. The CHAMP-1 programme investigates the potential contribution of pharmacists to optimise discussion of alcohol during routine practice. It is informed by prior work on brief interventions, which found no benefit to patients in community pharmacies (Dhital et al., 2015). Here we look at the wider contexts of the public health work in which alcohol is situated. By focusing on the "healthy-living advice' aspect of the MUR, we offer a case study of where public health advice is negotiated between pharmacist and 'patient'. MUR is designed to support patient adherence to 
treatment and resolve medicine-related problems (Latif, 2017). Since 2007, over four million MUR consultations have been conducted (Stewart et al., 2019).

Exploratory and feasibility observations were undertaken in ten community pharmacies in the North of England, featuring 14 community pharmacists, as part development of an intervention (Madden et al., 2020b). This involved shadowing pharmacists, observing their routine practice (including MUR consultations) and carrying out informal interviews as they conducted their work. Two researchers undertook 63 hours of observations and initiated focused conversations with pharmacists. Observations focused on understanding the working environment, recruitment of patients and conduct of reviews. The aims included identifying opportunities for person-centred discussion, including alcohol. Some early observation findings have been reported elsewhere (Morris et al., 2019). In addition, semi-structured interviews were conducted with seven of the pharmacists who took part in a later feasibility study, which informed the development of a pilot RCT.

Semi-structured interviews were also conducted with 25 people (16 men and nine women, mean age 64), who drank alcohol and took multiple medicines. These interviews explored whether they were open to the idea of talking with a pharmacist about alcohol as part of a medicines' review (Madden et al., 2020a). Interviewees were recruited from seven of the community pharmacies where observations had taken place. Interviews, conducted in participant's own homes and digitally recorded, used a topic guide, which comprised openended prompt questions on the use of medicines and alcohol; use of the pharmacy; experience of medicines reviews; and thoughts on talking about alcohol as part of a MUR.

Transcribed interviews and contemporaneous field-notes, narratively expanded by the researcher shortly after leaving the pharmacy, form the basis of our analysis. Some a-priori codes were established from the interview schedule and observation template, but detailed 
coding was developed through iterative retrospective analysis. The broader team checked the stability and reproducibility of coding. Analytical materials are understood as co-constructed through interactions between the participants and the researchers, whose interest in alcohol was transparent. These were organised using a modified framework method (Gale et al., 2013) which supported a constructionist thematic analysis (Braun and Clarke, 2006). Analysis of interaction is derived from observer field notes. The studies received UK Health Research Authority ethics approval (REC reference 17/YH/0406). Interview participants were given verbal and written information explaining the study aims and their involvement. Written consent was obtained and interviewees given assurances about confidentiality. Empirical analysis for this paper focused on pharmacists' discussion of healthy-living advice, within the context of competing demands, as they attempt to fulfil a broader clinical and public health role, consistent with protecting and enhancing their sense of professional standing. This included theoretically exploring the potential for 'pastoral care' to shape patients' 'self-regulating subjectivities' (Waring et al., 2016 p123).

\section{FINDINGS}

\section{Business as usual? In search of time and space, when managing competing demands}

Community pharmacies were busy environments. Many pharmacists (although not those working in independent pharmacies) reported pressure to achieve a target of 400 MURs per year (the current cap for remuneration):

Everything is a target, everything, because the Government's taking money from pharmacy and the only way to recoup...to get the money back is to do more services that increase the footfall in the pharmacy because if...there's no profit there's no business...the target is the patient... at the end of the day...you do not think MUR's 
appropriate for that patient but they say to you...just do it anyway (INV-I-PH-05: interview-intervention arm-pharmacist-number)

This pharmacist stated that by interpreting the cap as a 'target', MURs became an instrumental means to generate contractual income rather than deliver patient benefit. Targets were visible in some pharmacies on wall-posters, offering staff incentives:

I notice the 'biggest recruiter prize' on the wall in the dispensary for MURs. They get a free day off for winning (OBS-005: observation number).

Some pharmacists claimed that unnecessary MURs were being conducted in other pharmacies (but not their own), 'simply to get pay' (OBS-005), gaming the system. As found in previous studies, support staff identified eligible patients during routine dispensing (Latif et al., 2013). People waiting for prescriptions were asked if they had time for a 'quick chat' with the pharmacist. Most agreed that 'the difficult bit is getting them in there' (gestures at the consultation room) (OBS-002), without alienating the 'customer':

The way the assistant asks is very informal, not mentioning the...term, MUR...'You're actually due a little chat with [name of pharmacist], just to check you're OK, it will take only five minutes if that's OK' [Another member of support staff says] 'They've got no time, have they? Always in a rush' (OBS-005).

Those recruiting to MURs had strategies to minimise the chances of people saying 'no'. However, little explanation of context was provided and the potential value to the patient downplayed.

Most receiving a MUR appeared happy with the 'chat', but unclear about its purpose, with poor recall of its content (see Latif et al., 2018). For those with health-related queries, most expressed a preference to talk to their GP, who they believed better qualified to offer advice: 
I went to a pharmacy, well... just the pharmacy department in a big department store thing, and asked if they had any creams or something like that, sort of steroid type cream. I was prescribed something but it didn't do any good. So I then got a proper appointment [with the GP] and got the proper stuff (INV-Pat-22: Interview patient number).

A few reported feeling more comfortable talking about their health with a pharmacist. Pharmacists were seen to have more time, but also less opportunity to reinforce decisions:

I find it better with the pharmacist actually... because he seems to have more time for you...there's been a few times when I've wanted to talk to the doctor and... he gives me the impression that he hasn't got time for me...I think you get scared that [the GP] he's just going to stop your medication if you tell him the truth about anything...You don't really say anything with the GP because you know what his answer is going to be (INV-Pat-10).

Some knew their pharmacist but others regarded it as an impersonal service, supplemental to 'proper' advice from the GP.

The core dispensing function of community pharmacists (and associated commercial priorities) had to be juggled alongside the need to offer a professionally valued service. The material context of the pharmacy reinforced this tension, highlighting competing pressures on the use of time and space (MURs have to be conducted in a consultation room). Pharmacists who did not have another pharmacist to 'cover' felt 'under pressure' to return to the dispensary, especially if a queue was developing: 
Because in the shop people are waiting and they want you to hurry up because at the end of the day it's more targets as well...MURs should take about...ten to 15 minutes. What if you're taking about 20/25 minutes? The staff [say], oh, come out, do this, do that (INV-I-Ph5).

Without cover or with a competing demand on the room, pharmacists' experienced frequent interruptions:

At this point [pharmacy dispenser] pops his head through the sliding door and says, 'can I use the room for a C-card?' [free condoms for young people]. We begin to move our things...Less than a minute later [another member of pharmacy staff] pokes her head through sliding door and asks the pharmacist: 'Can I bring in an MUR?' We go out... and I walk to till area where I ask, 'is C-card happening in the consultation room or MUR?' She says, 'we are pushing for MURs today' so the C-card will be at the desk over there, she points to where [pharmacy dispenser] is already doing it (OBS-006).

Interruptions could give the impression that the consultation was not important, making it difficult to establish rapport, while offering a further reminder of the contrast between the standing of GPs and pharmacists.

Some pharmacists spoke about the particular difficulties of time management and choosing what to prioritise, seeking to avoid a backlog in dispensing. Services competing for consultation space with MURs included a range of private and NHS healthcare services: vaccinations; sexual health clinics; morning after contraception; HIV testing; and a remote independent prescriber service via webcam. NHS or local authority commissioned services vary regionally and in our sites, included some smoking cessation (also offered privately); 
blood pressure checks; minor ailment service; influenza vaccination and supervised methadone services.

Interruptions reflect the realities of routine practice. One pharmacist explained that his pharmacy was next door to a medical practice which had received a Care Quality Commission rating of 'inadequate'. His workload included people who could not get a GP appointment. The 'cover pharmacist' expected on the day of the observation had not arrived. That afternoon the pharmacist covered dispensing, fielded numerous telephone calls (including supply chain issues), advised customers at the counter, did two face-to-face MURs, a (telephone) new-medicines review and saw three people in the consultation room with potentially serious clinical issues. The consultation room was also occupied for some time by a pharmacy technician and a young man refusing to take his medications:

She comes out and says he is now saying he wants to die. The pharmacist asks if she thinks he is suicidal, does she want him to ring 111 ? They agree calling an ambulance may be provocative if he does not want to go to hospital. He got 'fobbed off' by a doctor yesterday. He has a rash. The technician agrees to go back in to advise him about the rash and see if they can arrange some cream. The pharmacist phones 111 but is on hold on the telephone for some time, then gives up. The pharmacist explains that the technician will spend some time listening to him and showing that she cares about what he says to see if that makes a difference. This keeps the room occupied. After some time he calms down. They come out and she gives him some cream (OBS 008).

\section{Ticking the healthy-living advice box}

Observed MUR consultations were short (mean length, 10 minutes) and although the guidance recommends using open, exploratory questions, most comprised closed questions to 
check if patients were taking medications, knew what they were taking them for; and identify any problems. Questions about healthy-living featured at the end of the consultation. A 'dataset form' is completed during or following each MUR (by 'ticking a box') to indicate the advice given. Policy (and service specifications) describe the MUR as an individually tailored patient-centred service (Latif et al., 2018). Pharmacists, however, tended to use the prescription-list to structure the consultation, conflating 'understanding' with 'reinforcement'. The dataset form encouraged this:

As a result of the MUR the pharmacist believes there will be an improvement in the patient's adherence to the medicine as a result of the following (more than one may apply):

a) better understanding/reinforcement of why they are using the medicine/what it is for;

b) better understanding/reinforcement of when/how to take the medicines;

c) better understanding/reinforcement of side effects and how to manage them;

d) better understanding/reinforcement of the condition being treated (PSNC, 2020b)

Towards the bottom of the form were a series of boxes to identify the healthy living advice provided (more than one might apply): Diet \& nutrition; Smoking; Physical activity; Alcohol; Sexual health; Weight management; Other. There was also a box 'Healthy living advice not applicable' (PSNC, 2020b).

Pharmacists perceived medicines safety and adherence as being the core purpose of the MUR (see Salter, 2010). They were confident in questioning patients about this, but ill-at-ease when probing 'healthy-living':

Pharmacist: Few other health related things- You smoke? 
Person: No

Pharmacist: Fruit and veg?

P: I have full dinners.

Pharmacist: Plenty of fresh veg with dinners?

P: Oh yes, but not fruit.

Pharmacist: Not keen?

P: Wouldn't go and buy it.

Pharmacist: That's fine.

Pharmacist: Physical activity?

P: I do plenty of walking.

Pharmacist: 20 minutes? Research suggests 20 minutes of walking a day is good for your heart.

P: I'm always rushing about. Can't sit still.

Pharmacist: Alcohol?

P: Tot of brandy

Pharmacist: At night before bed?

P: Yeah, brandy and coke

Pharmacist: I'll send a note to the GP. While I get that sorted out for you. Anything else? (OBS-005) 
When asked why he left all the healthy-living questions to the end, when it may have been more pertinent to raise them within the context of the health issues for which medicines were being taken, the pharmacist replied:

Because that's what we've always done. We focus on the medicines first because we are pharmacists (OBS-005).

Questions about 'healthy-living' gathered information with minimal exploration. Sometimes pharmacists offered 'common-sense' injunctions to exercise, eat well, drink moderately or provided leaflets (and information) detailing their services, such as smoking cessation. Some pharmacists avoided the questions altogether, while others rushed through them, focusing on one particular aspect and commenting more informally on their own behaviour:

Pharmacist: Ok, so do you smoke?

Person: No.

Pharmacist: Do you drink?

P: Yeah

Pharmacist: How often?

P: Once per week on a Saturday, the rest of the days are in the gym.

Pharmacist: Oh what do you do in the gym?

P: I do it day by day, cardio then weights. It's Monday-Friday.

Pharmacist: I just joined a gym and I find it very hard.

P: I used to do sports. Boxing, football but stopped around 50. I still play five a side once a week though.

Pharmacist: So you've always been active? 
P: Have to, have to do it.

Pharmacist: So they tell me. That's why I've joined the gym. Well, lovely chatting to you Mr [name] (OBS-006)

These exchanges provided opportunity for brief, light-hearted, informal interaction, but were rarely used to build rapport as the basis for a more meaningful consultation:

Pharmacist: One aspect of medicines, one that gets overlooked is healthy lifestyle. What about exercise, does not have to be $100 \mathrm{~m}$ sprint. Could be swimming, do you like that?

Person: [Older woman who has had knee replacement]. No. I stay active. I get out every day to go to a café. I have got one of those pedal things, on top of the heater in the garage.

Pharmacist: Good for you.

They joke about exercise equipment having an effect on their health from the garage. (OBS-012).

Pharmacists were especially concerned to avoid negative reactions, assuming people would not want to talk about 'difficult' topics like alcohol:

It's a subject that people don't want to talk [about]...you become expert in other things that people are...happy to discuss (INV-I-PH2).

Observed MURs offered little opportunity to explore health-related behaviours from the patient's viewpoint. The interactions confirmed the existing role of pharmacists as providing medicine safety advice, rather than supporting healthy-living choices. Patients often spoke in terms of providing information to the pharmacist rather than negotiating information: 
I was just in a way answering his questions because he was asking me about things wasn't he? (INV-002 PA).

Our observations of MURs echoed the findings of Latif et al (2018). These were polite encounters designed not to take up too much 'customer' or pharmacist time. MURs were further constrained by a business orientated organisational culture and the busy community pharmacy environment. Pharmacists and patients exchanged mainstream, 'common-sense' ideas about healthy-living, in ways that did not resemble a discussion likely to be helpful as a behavioural intervention.

An example demonstrates the challenges faced by community pharmacists, in offering 'pastoral care'. A woman prescribed medication for an underactive thyroid and anxiety, was offered a MUR:

Pharmacist asks, 'do you smoke'? The woman says 'yeah'. Pharmacist then asks 'have you ever considered quitting?' She says, 'No, I'm not ready' and explains that it helps with her anxiety. When she is panicky she goes outside and has a cigarette and it helps her feel better. Pharmacist then says that if you are ever ready you can come in here as we do smoking cessation and asks her whether she has tried e-cigarettes. The woman talks about how she did once but that she doesn't get much from them. Pharmacist then asks her how many she smokes a day. The woman says ' $15-20$ '. Pharmacist then says, 'it's one of the things you can do for your health, but you have to be ready to quit.' (OBS 006).

The woman went on to raise concerns about her weight. The pharmacist referred to information on the internet and suggested she see her doctor: 
The woman says she was also wondering if she could see a dietician to help her lose weight...it is getting her down that she has 'piled on the weight'. Pharmacist says, 'yes you can go to the doctor and get a referral but you can start with little changes. They make a difference'. The woman says that she is eating all the 'bad things, like chocolate' because she feels down, but she knows that does not help. Pharmacist then says, 'do you use the internet?' The woman nods, and pharmacist says that there is lots on there about what is in your food and 'you know the foods to avoid'. The woman explains that she wanted to do Slimming World but that she has no family up here and she's got two kids. Pharmacist offers the woman the scales in the appointment room as an option. She says you can always come in here once a week and weigh yourself. We can take readings too if you like when you are ready...She says that if you start taking the [thyroid medication] you won't lose weight because 'you've already piled it on, so you have to make an effort to lose the weight as well' (OBS 006).

While trying to be helpful, the pharmacist largely left the woman to her own devices, having to be 'ready to quit' smoking and needing to 'make an effort' to lose weight. Her anxiety was not addressed.

A second example demonstrates how information, rather than advice, was seen as sufficient to facilitate behavioural change. Most of the pharmacies we observed ran health promotion campaigns in response to local authority or other demands. Little proactive follow-up, however, was offered. One pharmacist who had managed a HLP for eight years said that pharmacies should be a 'platform for wellbeing' and a 'health hub', where people were able to browse information, while waiting for their medicines (OBS-001). In her own practice, this consisted of many leaflets and posters from numerous charities, in addition to alcohol 
industry sources, which is not without controversy (see McCambridge, 2014). She said providing information in leaflets might 'help people change'. A view expressed by many community pharmacists, who more generally, were comfortable with offering information or product-led services (such as nicotine replacement and smoking cessation) rather than a more discursive engagement, particularly on issues such as alcohol, with those who visited the shop.

\section{DISCUSSION}

Martin and Waring (2018) note that the literature on governmentality over-emphasises the control of patients and neglects how 'experts' are also disciplined through these governing rationalities (see also Miller and Rose, 2008). The 'pastoral' metaphor, conjuring the idea of flocks to be managed, can be extended to pharmacists as well as patients. In agreeing to act as conduits of disciplinary power, community pharmacists present opportunities for State regulation and intervention, thereby becoming subjects of disciplinary power themselves (Jones, 2018). 'Pastoral power' and 'the pharmacy gaze' are embedded in a broader governmentality which operates as a form of power that exploits professional ambiguity to 'manage' the subjectivities of community pharmacists working in an increasingly corporate retail environment. The direction from pharmacy leaders in response to economically and ideologically driven demands suggests the profession can increase its patient-facing role with minimal additional training, while continuing with its existing workload. This, while an understandable response to continuing threats to professional standing, struggles to reconcile pharmacy as a potential resource with clarification of what constitutes effective 'pharmacy care' (Todd et al, 2014). 
The public health activities observed largely comprised the instrumental provision of remunerated services that involved asking closed questions; offering 'common-sense' information or advice; and displaying and distributing leaflets. Healthy living discussions rarely involved any substantial exploration of people's medicines and health; or more generally, about how they lived their lives (see also Morton et al. 2015). The latest quality standard for promoting health and well-being in community pharmacies posits that informal conversations 'may encourage people to ask more questions, consider how they feel or how their behaviours may be affecting their health' (NICE, 2020). Interactions observed were friendly and transactional but rarely patient-centred or appreciative of an understanding of how behavioural change is aired or socially negotiated. Pharmacists continued to prioritise product safety (medicines) and customer satisfaction (business). The 'pharmacist gaze' during the MUR was on the list of medicines taken by the patient; checking that these were being taken as prescribed; and on the form to be completed. Issues raised by patients were not explored and the pharmacist gaze was averted from particularly uncomfortable areas like alcohol use.

Pharmacists frequently confused offering advice with a proactive and tailored engagement with the complex nuances of patient narratives. So, while accessible, they struggled to encourage people to act as active reflexive agents, making choices, supported by expert professional advice (Lupton, 2012). The provision (rather than negotiation) of information was seen as sufficient in encouraging patients to take responsibility for their own health. Consequently, pharmacists failed to begin to address the broader social determinants of health, consistent with the profession's public health aspirations (see Jesson and Bissell, 2006). Converting generic advice, meaningfully related to the broadening public health agenda, with the exercise of specialised knowledge, rarely occurred. Interventions for 
alcohol, and weight management that go beyond information and the offer of facilities for weighing, are particularly difficult to implement when compared to smoking cessation where an off-the-shelf product is available. They require person-centred skills, which according to professional and policy documents, pharmacists possess. Our empirical material suggests dissonance between an assumed professional ideal and its practical application.

Attempts to offer advice were further undermined by confusion about the purpose of the interactions we observed. Pharmacists found it difficult to offer clarity on the intent of healthy living advice within the context of a medicines-use review and lacked confidence when discussing areas they considered sensitive. Nor did they wish to upset their 'customers'. This uncertainty led patients to disregard information, particularly when they could not understand its relevance. Some people waiting for their medicines were happy to 'chat', but few accorded it a great deal of significance because this was not invited. This compared unfavourably to how patients viewed contact with GPs. Patient narratives do suggest a respect for the pharmacist's role and expertise (also see Hibbert et al., 2002), but this is conditional. Little understanding of community pharmacy's aspirations to offer an extended role was evident.

Closed pharmacist-led transactions, therefore, curtailed opportunities for 'pastoral care' (Waring et al., 2016). The aspirational evolution from an initial narrow, product-centred model to a more patient-centred model remained incomplete. Consequently, pharmacists fulfilled a rhetorical role in the governmentality of healthy living, and this seemed more effective in managing pharmacy practice than the actions of patients/customers. At organisational levels, the 'pharmacy gaze' was on financial targets. Dispensing and achieving contracted service targets left little time for pharmacists to actually spend with patients. MUR 
recruitment targets focus on those most likely to agree so excluding people with more complex needs and from medically underserved groups (Latif et al., 2019). Pharmacies were also affected by GP workforce shortages in primary care and, rather than a professional 'turfwar' with GPs, extended services were perceived as part of a bid for financial and professional survival and hope of a vaguely more patient-oriented future.

The requirement for community pharmacists to exercise expert knowledge, on issues about which they have little substantial previous engagement or formal education, while juggling competing tasks, within a mercantile environment, creates considerable challenges when establishing an effective and collaborative relationship with patients. Visible and audited performance seemingly assumed greater importance than meaningfully helping people. Consequently, an extended role risks exposing a lack of 'expert' knowledge rather than enhancing professional standing; reinforcing a confusion between public health expertise and 'common sense' injunctions; and creating the potential for community pharmacists to seem culpable if customer/patient self-care is not realised. By offering superficial sites of practice, a more obvious governmentality (and the associated fragility of underfunded primary care and public health services) is concealed and protected (see Petersen, 1997). The State's commitment to health-for-all, however, is visibly maintained.

Filling the evidence gap on health outcomes could help challenge professional ambiguity in community pharmacy if evaluation is informed by theory grounded in the dynamics of actual pharmacy and public health practice (Madden et al., 2020). Poorly evidenced top-down initiatives continue to be introduced with little involvement of those who deliver and receive them on whether the policy visions proposed for extending pharmacy are practical, desirable or meaningful to them. Pharmacies observed paid little proactive attention to population 
health intelligence or local community assets (Royal Pharmaceutical Society, 2014), but were expected to respond promptly and politely to whatever came in through the door. There was no evidence of a public health gaze on the wider social and economic determinants of health. This was further outside the pharmacy gaze than a limited version of 'lifestyle medicine' focused on getting people to 'take responsibility' for their health (Sayburn, 2018).To successfully utilise the potential future presented by a public health role, community pharmacists could usefully explore how best to support an individual to manage the context, in which they have to realise healthy lifestyles, where inequality creates differential health outcomes (Popay et al., 2010). Bridging the gap between pharmaceutical and social prescribing practices (Bickerdike et al., 2017), for example, could ensure meaningful and grounded advice that improved the potential for healthy outcomes. This utilises the public heath space offered and affords some protection against the subverting and eroding challenges posed by 'McDonaldization', in which standardisation, particularly the need to offer short-term, institutionally-specific returns rather than long-term, cumulative effect, constrains the exercise of professional discretion.

The difficulties community pharmacists face in negotiating the more individualistic tendencies in healthcare offer little substantial protection against becoming passive vessels for the enactment of consumerist healthcare policies. Discursive practices are not, however, merely textual or abstract, but realised through social practices. Power (and governmentality) is pervasive but negotiable (Martin and Waring, 2018). Questioning how community pharmacy currently imagines public health may offer a more appropriate basis on which to develop more sustainable claims to professional status. This implies a more critical regard for how the 'art of living' (Rose, 2009) becomes defined through the process of social negotiation (Marsland and Prince, 2012). Such an approach forms the basis on which 
community pharmacy can challenge existing practices and offer alternative futures. In doing so, it can move beyond the technical act of prescribing medicines, to one more consistent with broader definitions of medicine as a 'social good' (see Harding and Taylor, 1997). Engaging with normative assumptions and understanding how patients conceptualise healthy living, represent valuable starting points.

\section{ACKNOWLEDGEMENTS}

Thanks to the pharmacists and patients who participated in or advised on this study.

This research was funded by the National Institute for Health Research [NIHR] PGfAR [RPPG-0216-20002]. The views expressed are those of the authors and not necessarily those of the NIHR or the Department of Health and Social Care.

\section{ADDRESS FOR CORRESPONDENCE}

Mental Health and Addiction Research Group, Department of Health Sciences, Faculty of Science, Area 4, Seebohm Rowntree Building, University of York, Heslington, York YO10 5DD. Email: karl.atkin@york.ac.uk

\section{REFERENCES}

ANDERSON, C., BLENKINSOPP, A. \& ARMSTRONG, M. 2003. Pharmacists' perceptions regarding their contribution to improving the public's health: a systematic review of the United Kingdom and international literature 1990-2001. International Journal of Pharmacy Practice, 11, 111120.

BICKERDIKE, L., BOOTH, A., WILSON, P. M., FARLEY, K. \& WRIGHT, K. 2017. Social prescribing: less rhetoric and more reality. A systematic review of the evidence. BMJ Open, 7, e013384.

BRAUN, V. \& CLARKE, V. 2006. Using thematic analysis in psychology. Qualitative Research in Psychology, 3, 77-101.

BROWN, W. 2015. Undoing the demos: Neoliberalism's stealth revolution, New York, Zone Books. BUSH, J., LANGLEY, C. A. \& WILSON, K. A. 2009. The corporatization of community pharmacy: implications for service provision, the public health function, and pharmacy's claims to professional status in the United Kingdom. Res Social Adm Pharm, 5, 305-18. 
CHEMIST + DRUGGIST. 2019. Stress levels in community pharmacy: data from the $C+D$ Salary Survey 2014-2018 Available: https://drive.google.com/file/d/1fALPx4F807HUrRfChVzlT9Rd3pbTPc6/view

COOPER, R. J. 2020. Pestle and mortal: the demise of community pharmacy in the UK. International Journal of Pharmacy Practice, 28, 205-206.

COOPER, R. J., BISSELL, P. \& WINGFIELD, J. 2009. 'Islands' and 'doctor's tool': the ethical significance of isolation and subordination in UK community pharmacy. Health (London), 13, 297-316.

DENZIN, N. \& METTLIN, C. 1968. Incomplete Professionalization: The Case of Pharmacy. Social Forces., 46, 375-381.

DEPARTMENT OF HEALTH AND SOCIAL CARE 2019. The Community Pharmacy Contractual Framework for 2019/20 to 2023/24: supporting delivery for the NHS Long Term Plan.

DEPARTMENT OF HEALTH. 2016. Community Pharmacy in 2016/17 and beyond Impact assessment. London: Department of Health.

DHITAL, R., NORMAN, I., WHITTLESEA, C., MURRELLS, T. \& MCCAMBRIDGE, J. 2015. The effectiveness of brief alcohol interventions delivered by community pharmacists: randomised controlled trial. Addiction, 110, 1586-1594.

DINGWALL, R. 2008. Essays on Professions Aldershot, Ashgate.

EADES, C. E., FERGUSON, J. S. \& O'CARROLL, R. E. 2011. Public health in community pharmacy: A systematic review of pharmacist and consumer views. BMC Public Health, 11, 582.

ELVEY, R., HASSELL, K. \& HALL, J. 2013. Who do you think you are? Pharmacists' perceptions of their professional identity. International Journal of Pharmacy Practice, 21, 322-332.

FINCH, I. 2018. Can you make a Botox and dermal filler service work in your pharmacy? Chemist +Druggist. Available: https://www.chemistanddruggist.co.uk/feature/can-you-make-botoxtreatment-service-work-your-pharmacy

FOUCAULT, M. 2007. Security, Territory, Population. London, Palgrave Macmillan.

GALE, N. K., HEATH, G., CAMERON, E., RASHID, S. \& REDWOOD, S. 2013. Using the framework method for the analysis of qualitative data in multi-disciplinary health research. $B M C$ Medical Research Methodology, 13.

GODLEE, F. 2019. How much medicine is too much? BMJ, 364, 1902.

HANN, M., SCHAFHEUTLE, E. I., BRADLEY, F., ELVEY, R., WAGNER, A., HALSALL, D., HASSELL, K. \& JACOBS, S. 2017. Organisational and extraorganisational determinants of volume of service delivery by English community pharmacies: a cross-sectional survey and secondary data analysis. BMJ Open, 7, e017843.

HARDING, G. \& TAYLOR, K. 1997. Responding to change: the case of community pharmacy in Great Britain. Sociology of Health \& IIIness, 19, 547-560.

HARDING, G. \& TAYLOR, K. 2000. The McDonaldization of pharmacy. Pharmaceutical Journal 265,602

HEALTH FOUNDATION AND KINGS FUND. 2019. Urgent call for $f 1 b n$ a year to reverse cuts to public health funding. Available: https://www.health.org.uk/news-and-comment/news/urgent-callfor-1-billion-a-year-to-reverse-cuts-to-public-health-grant

HIBBERT, D., BISSELL, P. \& WARD, P. R. 2002. Consumerism and professional work in the community pharmacy. Sociology of Health \& IIIness, 24, 46-65.

IACOBUCCI, G. 2017. A service under pressure. BMJ, 356, i6691.

JAMIE, K. 2014. The pharmacy gaze: bodies in pharmacy practice. Sociology of Health \& IIIness, 36, 1141-1155.

JESSON, J. \& BISSELL, P. 2006. Public health and pharmacy: A critical review. Critical Public Health, $16,159-169$.

JONES, L. 2018. Pastoral power and the promotion of self-care. Sociology of Health \& IIIness, 40, 9881004.

KICKBUSCH, I. \& PAYNE, L. 2003. Twenty-first century health promotion: the public health revolution meets the wellness revolution. Health Promot Int, 18, 275-8. 
LANGLEY, C., BUSH, J. \& PATEL, A. 2014. Implementation and Impact of Healthy Living Pharmacies within the Heart of Birmingham. Birmingham: Aston Pharmacy School

LATIF, A. 2017. Community pharmacy Medicines Use Review: current challenges. Integrated Pharmacy Research and Practice, 7, 83-92.

LATIF, A., BOARDMAN, H. F. \& POLLOCK, K. 2013. A qualitative study exploring the impact and consequence of the medicines use review service on pharmacy support-staff. Pharmacy Practice (Granada), 11, 118-24.

LATIF, A., WARING, J., WATMOUGH, D., BOYD, M. J. \& ELLIOTT, R. A. 2018. "I expected just to walk in, get my tablets and then walk out': on framing new community pharmacy services in the English healthcare system. Sociology of Health \& IIIness, 40, 1019-1036.

LATIF, A., WARING, J., CHEN, L.-C., POLLOCK, K., SOLOMON, J., GULZAR, N., GULZAR, S., ANDERSON, E., CHOUDHARY, S., ABBASI, N., WHARRAD, H. J. \& ANDERSON, C. 2019. Supporting the provision of pharmacy medication reviews to marginalised (medically underserved) groups: a before/after questionnaire study investigating the impact of a patient-professional coproduced digital educational intervention. BMJ Open, 9, e031548.

LIPSKY, M. 2010. Street Level Bureaucracy: Dilemmas of the Individual in Public Services. 30th Anniversary Expanded Edition, New York, The Russell Sage Foundation.

LUPTON, D. 2012. Medicine as culture: illness, disease and the body. London, Sage.

MACKRIDGE, A. J., GRAY, N. J. \& KRSKA, J. 2017. A cross-sectional study using freedom of information requests to evaluate variation in local authority commissioning of community pharmacy public health services in England. BMJ Open, 7, e015511.

MADDEN, M., MORRIS, S., ATKIN, K., GOUGH, B. \& MCCAMBRIDGE, J. 2020a. Patient perspectives on discussing alcohol as part of medicines review in community pharmacies. Research in Social and Administrative Pharmacy, 16, 96-101.

MADDEN, M., MORRIS, S., OGDEN, M., LEWIS, D., STEWART, D. \& MCCAMBRIDGE, J. 2020b. Producing co-production: Reflections on the development of a complex intervention. Health Expectations.

MARSLAND, R. \& PRINCE, R. 2012. What Is Life Worth? Exploring Biomedical Interventions, Survival, and the Politics of Life. Medical Anthropology Quarterly, 26, 453-469.

MARTIN, G. P. \& WARING, J. 2018. Realising governmentality: Pastoral power, governmental discourse and the (re)constitution of subjectivities. The Sociological Review, 66, 1292-1308.

MCDONALD, R., CHERAGHI-SOHI, S., SANDERS, C. \& ASHCROFT, D. 2010. Professional status in a changing world: The case of medicines use reviews in English community pharmacy. Social Science and Medicine, 71, 451-458.

MILLER, P. \& ROSE, N. 2008 Governing the Present: Administering Economic, Social and Personal Life. Cambridge, Polity.

MORRIS, S., MADDEN, M., GOUGH, B., ATKIN, K. \& MCCAMBRIDGE, J. 2019. Missing in action: Insights from an exploratory ethnographic observation study of alcohol in everyday UK community pharmacy practice. Drug and Alcohol Review, 38, 561-568.

MORTON, K., PATTISON, H., LANGLEY, C. \& POWELL, R. A qualitative study of English community pharmacists' experiences of providing lifestyle advice to patients with cardiovascular disease. Research in Social and Administrative Pharmacy, 11, e17-e29.

MURRAY, R. 2016. Community Pharmacy Clinical Services Review London: NHS England Available: https://www.england.nhs.uk/commissioning/wpcontent/uploads/sites/12/2016/12/community-pharm-clncl-serv-rev.pdf

NAZAR, Z. J., NAZAR, H., WHITE, S. \& RUTTER, P. 2019. A systematic review of the outcome data supporting the Healthy Living Pharmacy concept and lessons from its implementation. PLOS ONE, 14, e0213607.

NHS. 2019. The NHS Long Term Plan. Available: https://www.longtermplan.nhs.uk/publication/nhslong-term-plan/ 
NICE. 2020 Community pharmacies: promoting health and wellbeing NICE quality standard. Available: https://www.nice.org.uk/guidance/indevelopment/gid-qs10115/documents

NUFFIELD COMMITTEE OF INQUIRY INTO PHARMACY. 1986. Pharmacy: a Report to the Nuffield Foundation. London: The Nuffield Foundation.

PETERSEN, A. 1997. Risk, governance and the new public health In: BUNTON, A \& PETERSEN,R (eds.) Foucault, Health and Medicine. London: Routledge.

POPAY, J., WHITEHEAD, M. \& HUNTER, D. J. 2010. Injustice is killing people on a large scale-but what is to be done about it? Journal of Public Health, 32, 148-149.

PSNC. 2020a. Healthy Living Pharmacies. Available: https://psnc.org.uk/servicescommissioning/locally-commissioned-services/healthy-living-pharmacies/

PSNC. 2020b. MUR record keeping and data requirements. Available: https://psnc.org.uk/murrecord-keeping-and-data-requirements/

PSNC AND NHS EMPLOYERS. 2012 Guidance on the medicine use review service. London: Department of Health.

PUBLIC HEALTH ENGLAND AND ROYAL SOCIETY FOR PUBLIC HEALTH. 2016. Building capacity: realising the potential of community pharmacy assets for improving the public's health. London: PHE and RSPH.

RITZER, G. M. \& ELIZABETH, L. 2000. Globalization Theory: Lessons from the Exportation of McDonaldization and the New Means of Consumption. American Studies, 41, 97-118.

ROSE, N. 2007. The Politics of Life Itself: Biomedicine, Power, and Subjectivity in the Twenty-first Century. London, Routledge.

ROSE, N. 2009. Normality and Pathology in a Biomedical Age. The Sociological Review, 57, 66-83.

ROYAL PHARMACEUTICAL SOCIETY. 2014. Professional Standards for Public Health Practice for Pharmacy. London: RPS.

SALTER, C. 2010. Compliance and concordance during domiciliary medication review involving pharmacists and older people. Sociology of Health \& IIIness, 32, 21-36.

SAYBURN, A. 2018. Lifestyle medicine: a new medical specialty? BMJ, 363, k4442.

STEWART, D., WHITTLESEA, C., DHITAL, R., NEWBOULD, L. \& MCCAMBRIDGE, J. 2019. Community pharmacist led medication reviews in the UK: A scoping review of the medicines use review and the new medicine service literatures. Research in Social and Administrative Pharmacy.

TAYLOR, K. \& HARDING, K. G. 2003. Corporate Pharmacy: Implications for the Pharmacy Profession, Researchers and Teachers. Pharmacy Education, 3.

THOMSON, K., HILLIER-BROWN, F., WALTON, N., BILAJ, M., BAMBRA, C. \& TODD, A. 2019. The effects of community pharmacy-delivered public health interventions on population health and health inequalities: A review of reviews. Preventive Medicine, 124, 98-109.

TODD, A., COPELAND, A., HUSBAND, A., KASIM, A. \& BAMBRA, C. 2014. The positive pharmacy care law: an area-level analysis of the relationship between community pharmacy distribution, urbanity and social deprivation in England. BMJ Open, 4, e005764.

WALKER, R. 2000. Pharmaceutical public health: the end of pharmaceutical care? The Pharmaceutical Journal, 264, 340-341.

WARING, J. \& BISHOP, S. 2011. Healthcare identities at the crossroads of service modernisation: the transfer of NHS clinicians to the independent sector? Sociology of Health \& IIIness, 33, 661676.

WARING, J., LATIF, A., BOYD, M., BARBER, N. \& ELLIOTT, R. 2016. Pastoral power in the community pharmacy: A Foucauldian analysis of services to promote patient adherence to new medicine use. Social Science \& Medicine, 148, 123-30. 